\title{
Mania Induzida por Mirtazapina: Um Caso Clínico
}

\section{Mirtazapine-Induced Mania: A Case Report}

\author{
Catarina FREITAS $\square^{1}$, Rui BARRANHA², Tânia ABREU ${ }^{2}$, Orlando VON DOELLINGER ${ }^{2}$ \\ Acta Med Port 2019 Oct;32(10):671-673 - https://doi.org/10.20344/amp.9916
}

\section{RESUMO}

O desenvolvimento de estados maníacos e hipomaníacos associado ao uso de antidepressivos é relativamente comum. Contudo, no caso da mirtazapina, este é um efeito secundário raro. Os autores descrevem um caso clínico de um episódio maníaco de características disfóricas, num doente sem antecedentes psiquiátricos pessoais ou familiares, com instalação duas semanas após início de tratamento com mirtazapina até $30 \mathrm{mg} / \mathrm{dia}$. Uma vez suspensa a mirtazapina e iniciada olanzapina (10 mg) verificou-se remissão sintomática. A mirtazapina apresenta uma farmacodinâmica particular, sendo antagonista não só de recetores serotoninérgicos póssinápticos, mas também de recetores adrenérgicos pré-sinápticos $\alpha 2$. Neste sentido, colocou-se a hipótese de se tratar de uma síndrome noradrenérgica, caracterizada por disforia, irritabilidade, insónia e agitação psicomotora.

Palavras-chave: Antidepressivos Tricíclicos/efeitos adversos; Mirtazapina/efeitos adversos; Perturbação Bipolar/induzida quimicamente

\section{ABSTRACT}

Manic and hypomanic states associated with antidepressant treatments are relatively common; however, when specifically considering mirtazapine, those side effects are infrequent. The authors report a clinical case regarding a manic episode with dysphoric features in a patient with no personal or family previous psychiatric history. It began two weeks after starting treatment with mirtazapine up to $30 \mathrm{mg} /$ day. This episode was treated discontinuing mirtazapine and initiating olanzapine $(10 \mathrm{mg})$, with symptomatic remission. Mirtazapine has a specific pharmacodynamics, blocking not only post-synaptic serotonergic receptors but also a2-presynaptic adrenergic receptors. Taking this into consideration, it was hypothesized that this case could be attributed to a noradrenergic syndrome, characterized by dysphoria, irritability, insomnia and psychomotor agitation.

Keywords: Antidepressive Agents, Tricyclic/adverse effects; Bipolar Disorder/chemically induced; Mirtazapine/adverse effects

\section{INTRODUÇÃO}

O desenvolvimento de estados maníacos e hipomaníacos associado ao uso de antidepressivos é relativamente comum, devendo-se maioritariamente ao uso de antidepressivos tricíclicos, inibidores da recaptação da serotonina e noradrenalina e inibidores seletivos de recaptação da serotonina (ISRS). ${ }^{1}$

A mirtazapina é um antidepressivo que possui uma farmacodinâmica atípica, atuando como antagonista dos receptores adrenérgicos pré-sinápticos $\alpha 2$, dos receptores serotoninérgicos pós-sinápticos das subfamílias $5-\mathrm{HT}_{2}$ e $5-\mathrm{HT}_{3}$ e dos receptores histaminérgicos $\mathrm{H} 1$. Presume-se que a mirtazapina aumente a neurotransmissão noradrenérgica e serotoninérgica, contudo, o número de casos reportados de estados maníacos induzidos pelo seu uso é baixo, assumindo-se como um efeito lateral raro.

Wichniak et $a^{\mathbb{R}}$ procederam a uma revisão dos casos reportados de episódios maníacos ou hipomaníacos ('viragens') associados a tratamentos com mirtazapina, até à data da publicação, concluindo que estes se resumiriam a dez doentes. Da análise dos resultados apresentados por estes autores, constatou-se que o efeito lateral em questão ocorreu utilizando doses inferiores a $30 \mathrm{mg} / \mathrm{dia}$ em apenas três casos. Num destes casos o doente fazia, simultaneamente, sertralina em doses elevadas (250 mg/dia) e um outro foi diagnosticado como 'depressão orgânica pós-AVC'. Três dos dez casos descritos foram referentes a tratamentos com doses antidepressivas de mirtazapina
(30 - $45 \mathrm{mg} / \mathrm{dia}$ ) em monoterapia, com um destes a ocorrer num doente idoso após suspensão de fluoxetina e início de mirtazapina sem período de washout. Em dois casos, as doses antidepressivas foram combinadas com ISRS. Adicionalmente, num doente, o estado hipomaníaco ocorreu em monoterapia com mirtazapina após subida de dose para $60 \mathrm{mg} / \mathrm{dia}$. O último dos casos dizia respeito a um doente idoso no qual ocorreu uma 'viragem' hipomaníaca após descontinuação de mirtazapina.

Após pesquisa na base de dados PubMed, verificou-se que, posteriormente à revisão em questão, apenas foi publicado mais um caso clínico sobre este tema, relatando um estado maníaco induzido após suspensão de mirtazapina. ${ }^{3}$

O presente artigo tem como objetivos descrever um caso clínico de um episódio maníaco num doente medicado com mirtazapina, em doses terapêuticas, e associar etiologias e características clínicas encontradas na literatura com o presente caso.

\section{CASO CLÍNICO}

O doente, um homem de 58 anos de idade, casado e trabalhador agrícola, foi referenciado a consulta de Psiquiatria pelo Médico de Família por queixas ansiosas e mnésicas, sono polifragmentado e anorexia, com cerca de um ano de evolução.

O doente não apresentava qualquer história psiquiátrica prévia, nomeadamente episódios depressivos ou (hipo) maníacos, consumo de tóxicos ou medicação psicotrópica,

\footnotetext{
1. Departamento de Psiquiatria e Saúde Mental. Centro Hospitalar de Trás-os-Montes e Alto Douro. Vila Real. Portugal.

2. Departamento de Psiquiatria e Saúde Mental. Centro Hospitalar do Tâmega e Sousa. Penafiel. Portugal.

$\bowtie$ Autor correspondente: Catarina Freitas. Catarinafreitas.freitas@gmail.com

Recebido: 10 de novembro de 2017 - 24 de abril de 2019 | Copyright @ Ordem dos Médicos 2019
} 
bem como antecedentes familiares psiquiátricos de relevo. Da sua história médica salientou-se que foi submetido, cerca de um ano e meio antes, a lobectomia pulmonar inferior esquerda por adenocarcinoma do pulmão pT1A N0 R0 M0 e apresentava esteatose hepática e hipertensão arterial.

Na primeira observação em consulta de Psiquiatria, foi colhida a história clínica, apresentando-se o doente com humor subdepressivo com tonalidade ansiosa, sem outras alterações ao exame do estado mental e pontuando $27 / 30$ no Mini-Mental State Examination.

Foi diagnosticado com uma provável reação de ajustamento com sintomatologia ansiosa e depressiva, em relação com a neoplasia pulmonar e as dificuldades de adaptação às limitações daí resultantes, nomeadamente para o trabalho. Realizou tomografia computorizada cerebral, que não mostrou alterações, mas com indicação para realização de ressonância magnética cerebral (pelos antecedentes). Uma vez que também a ressonância magnética não evidenciou qualquer alteração, o doente foi medicado com mirtazapina até $30 \mathrm{mg} /$ dia.

Duas semanas após o início da medicação (uma semana depois da dose de $30 \mathrm{mg} / \mathrm{dia}$ ), o doente desenvolveu um quadro de alteração do comportamento caracterizado por insónia quase total, verborreia, taquipsiquismo, inquietação psicomotora, humor disfórico e ideias sobrevalorizadas de teor persecutório. Foi, por isso, diagnosticado um episódio maníaco com características disfóricas, induzido por mirtazapina. Suspensa a mirtazapina e introduzida olanzapina $10 \mathrm{mg} / \mathrm{dia}$, o quadro em questão remitiu totalmente ao fim de uma semana, tendo o doente interrompido a medicação, por iniciativa própria, ao fim da segunda semana de tratamento.

Na observação ocorrida à terceira semana após a alteração terapêutica efetuada, o doente, já sem evidência de sintomatologia maniforme, apresentava, novamente, queixas predominantes de ansiedade, distractibilidade e perturbação do sono. Foi medicado com pregabalina (75 mg/dia), com remissão sintomatológica, mantendo-se estável nos seis meses seguintes.

\section{DISCUSSÃO E CONCLUSÃO}

A 'viragem' maníaca ou hipomaníaca associada à mirtazapina é rara $(0,25 \%$ em ensaios clínicos, com alguns casos reportados em indivíduos predispostos ${ }^{4}$ ).

Nos onze casos previamente citados, foram utilizadas diferentes doses de mirtazapina $(15 \mathrm{mg}$, três casos; 22,5 mg, um caso; $30 \mathrm{mg}$, quatro casos; $45 \mathrm{mg}$, dois casos; $60 \mathrm{mg}$, um caso). Em três desses casos, outros ISRS estavam a ser usados concomitantemente e num outro caso, foi iniciada mirtazapina sem washout do ISRI. Dois casos ocorreram após descontinuação da mirtazapina. Excluindo estes dois últimos casos, o tempo médio de início do quadro de elação do humor após o início do tratamento com mirtazapina, foi de 15,7 dias (mínimo de 3; máximo de 56; com uma mediana de 7 dias). Seis dos onze casos apresentaram um quadro de mania, quatro apresentaram hipomania e um apresentou um episódio misto.

O caso presentemente descrito é o único que ocorreu com a dose de $30 \mathrm{mg}$, sem toma concomitante ou anterior de outro antidepressivo. O tempo decorrido até ao início do quadro maníaco, neste caso, foi de duas semanas, o que está de acordo com a média de tempo descrita na literatura.

Relativamente ao tipo de episódio, tratou-se de uma mania com características disfóricas, o que está em consonância com os oito casos descritos num artigo, em que a hipótese do efeito noradrenérgico foi descrita como possível etiologia. ${ }^{5}$ Segundo esta hipótese, o bloqueio central dos auto e heterorrecetores a2 aumenta a neurotransmissão de serotonina e de noradrenalina, enquanto bloqueia os recetores pós-sinápticos $5-\mathrm{HT}_{2}$ e $5-\mathrm{HT}_{3}$, o que pode contribuir para a síndrome serotoninérgica ou noradrenérgica, ${ }^{6}$ ambas descritas na monoterapia com mirtazapina ou na combinação com ISRS. ${ }^{7-9}$

As características da síndrome noradrenérgica são diferentes das da síndrome serotoninérgica, com um quadro clínico definido por disforia, irritabilidade, insónia, agitação psicomotora, com menos sintomas autonómicos, tal como no caso descrito. Os fatores predisponentes para as duas síndromes não são conhecidos, sendo possível que existam diferentes mecanismos implicados.

\section{OBSERVAÇÕES}

Este trabalho foi apresentado previamente como comunicação oral no XVII WPA World Congress of Psychiatry, em Berlim, a 12 de outubro de 2017.

\section{PROTECÇÃO DE PESSOAS E ANIMAIS}

Os autores declaram que os procedimentos seguidos estavam de acordo com os regulamentos estabelecidos pelos responsáveis da Comissão de Investigação Clínica e Ética e de acordo com a Declaração de Helsínquia da Associação Médica Mundial.

\section{CONFIDENCIALIDADE DOS DADOS}

Os autores declaram ter seguido os protocolos do seu centro de trabalho acerca da publicação de dados.

\section{CONSENTIMENTO DO DOENTE}

Obtido.

\section{CONFLITOS DE INTERESSE}

Os autores declaram não ter nenhum conflito de interesses relativamente ao presente artigo.

\section{FONTES DE FINANCIAMENTO}

Não existiram fontes externas de financiamento para a realização deste artigo. 


\section{REFERÊNCIAS}

1. Goldberg JF, Truman CJ. Antidepressant-induced mania: an overview of current controversies. Bipolar Disord. 2003;5:407-20.

2. Wichniak A, Jarkiewicz M, Okruszek $九$, Wierzbicka A, Holka-Pokorska J, Rybakowski JK. Low risk for switch to mania during treatment with sleep promoting antidepressants. Pharmacopsychiatry. 2015;48:83-8.

3. Verma JK, Mohapatra S. Mirtazapine withdrawal-induced mania. J Pharmacol Pharmacother. 2015;6:214-5.

4. Montgomery SA. Safety of mirtazapine: a review. Int Clin Psychopharmacology. 1995;10:37-45.

5. Bhanji NH, Margolese HC, Saint-Laurent M, Chouinard G. Dysphoric mania induced by high dose mirtazapine: a case for 'norepinephrine syndrome'? Int Clin Psychopharmacol. 2002;17:319-22.

6. Stahl SM. Essential psychopharmacology: neuro-scientific basis and practical applications. Cambridge: Cambridge University Press; 2010

7. Hernandez JL, Ramos FJ, Infante J, Rebollo M, Gonzalez-Macias J. Severe serotonin syndrome induced by mirtazapine monotherapy. Ann Pharmacother. 2002;36:641-3.

8. Benazzi F. Serotonin syndrome with mirtazapine- fluoxetine combination. Int J Geriatr Psychiatry. 1998;13:495-6.

9. Demers JC, Malone M. Serotonin syndrome induced by fluvoxamine and mirtazapine. Ann Pharmacother. 2008;35:1217-20.

\section{Desafios Diagnósticos e Terapêuticos na Síndrome}

Sofia REIS D1, Daniela RAMOS2, Carolina CORDINHA $\tilde{A}^{3}$, Clara GOMES
Acta Med Port 2019 Oct:32(10):673-675 = httos://doi ora/10, 20344/amo 10021

RESUIMO

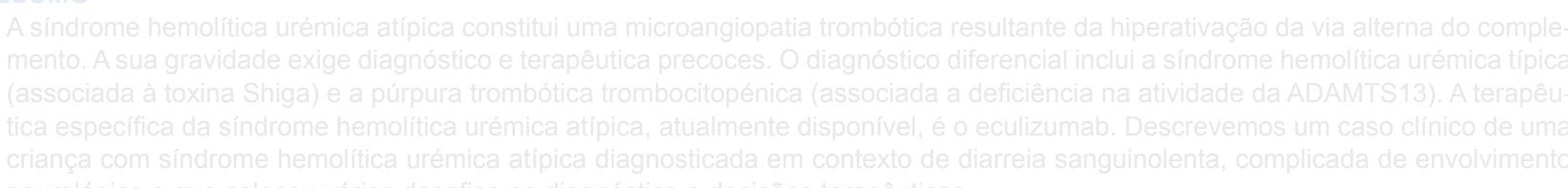

Palavras-chave: Eculizumab; Sindrome Hemolítica Urémica Atípica

\section{ABSTRACT}

The atypical hemolytic uremic syndrome comprises a thrombotic microangiopathy resulting from the complement alternate pathway
hyperactivation. Its severity requires early diagnosis and treatment. The differential diagnosis includes typical hemolytic uremic syn-
drome (associated with Shiga toxin) and thrombotic thrombocytopenic purpura (associated with deficient activity of ADAMTS13). The
only specific treatment currently available for atypical hemolytic uremic syndrome is eculizumab. We describe the case of a child with
atypical hemolytic uremic syndrome diagnosed in the context of bloody diarrhea, complicated by neurological involvement that posed

Keywords: Atypical Hemolytic Uremic Syndrome; Eculizumab

\section{INTRODUÇÃC}

